\title{
Radiobiological rationale for stereotactic hypofractionated radiosurgery Part II. Normal tissue tolerance - dose constraints
}

\author{
Bogusław Maciejewski ${ }^{1}$, Sławomir Blamek ${ }^{1}$, Krzysztof Składowski², Rafał Suwiński ${ }^{3}$, Leszek \\ Miszczyk ${ }^{1}$, Krzysztof Ślosarek ${ }^{4}$, Marcin Miszczyk ${ }^{4}$
}

The response of normal tissues/organs to SHRS is more complex than to conventional radiotherapy. Tolerance doses $\mathrm{TD}_{5 / 5}$ and $\mathrm{TD}_{50 / 5}$, proposed by Rubin and Casarett, cannot be simply used for SHRS. Instead of LQED $2^{\prime}$ the BED is advised. The term risk dose (RD) corresponds better than TD to the risk of late morphological and functional disorders (OAR). BED doses show a rapid gradient with increasing distance of the OAR from the tumour GTV. Other risk factors include the dose-volume relationship, OAR organization (serial or parallel) and the ratio of the FSU to the target call. Vasculoendothelial cell damage initiates series of processes resulting in clinical and functional late effect. Using available data and studies, $\mathrm{RD}_{\min }$ and $\mathrm{RD}_{\max }$ for doses are listed as physical and $\mathrm{BED}$ doses for various OAR and dose-volume constraints. The RD values and constraints are rough estimates, since the available SHRS data are sparse and fragmentary, which should be interpreted cautiously and need further clinical validation.

NOWOTWORY J Oncol 2018; 68, 2: 77-84

Key words: SHRS, risk doses, OAR late effects, radiobiological mechanisms

\section{Radiobiologic mechanisms}

For decades, knowledge about the pathoradiobiology and kinetics of normal tissues has been gathered mainly for conventional dose fractionation [1-4]. The radiopathology underlying late responses to SHRS is much less known [5]. Categorization of acute reactions (often transient) developing in hierarchical and late effects in flexible tissues may be misleading, since tissues/organs comprise more than one type of cells, each with its own characteristics [1]. Malnutrition and microenvironmental disfunction contribute to the death of target cells, and part of them (the residual pool) can be recruited to the proliferative pool, inducing "avalanche" cell death and functional disorders [1].
In SHRS there is a response similar to tumour response, except that the $5 R^{\prime}$ 's acute and late effects are also regulated by the 3R's [4-7]. The response to a few large doses compared to many conventional $2.0 \mathrm{~Gy}$ fractions can be anecdotally compared to a "boxing game". One challenger is knocked-down in the first round by a single strong punch, and another one also loses, but by points in the $15^{\text {th }}$ round, receiving many blows during each round. The first one will probably recover sooner, whereas the second one, who was physically and functionally devastated, would need a longer time to recover. This simple example reflects Fowler's statement $a$ lot to a little (volume) is better than not too much to a lot. With no doubt, the first part is a key principle underlying hypofractionated radiosurgery.

\footnotetext{
${ }^{1}$ Department of Radiotherapy, Maria Skłodowska-Curie Memorial Cancer Centre and Institute of Oncology, Branch in Gliwice, Poland

${ }^{2} 1^{\text {st }}$ Clinic of Radiotherapy and Chemotherapy, Maria Skłodowska-Curie Memorial Cancer Centre and Institute of Oncology, Branch in Gliwice, Poland

${ }^{3} 3^{\text {rd }}$ Clinic of Radiotherapy and Chemotherapy, Maria Skłodowska-Curie Memorial Cancer Centre and Institute of Oncology, Branch in Gliwice, Poland

${ }^{4}$ Department Radiotherapy Treatment Planning, Maria Skłodowska-Curie Memorial Cancer Centre and Institute of Oncology, Branch in Gliwice, Poland
} 
The number of serial or parallel functional subunits (FSU) with the number of target cells (TC), and volume effect significantly influence the incidence and severity of late radiation injury induced by conventional fraction doses, and the LQED 2 formalism has been proven as adequate for estimating and comparing equivalent doses [1]. However, it unlikely that it would work for SHRS, which uses large fractions. An indisputably advantageous characteristic of the SHRS is a lot to a little. A large dose is at least intentionally homogeneously distributed within the tumour GTV with pronounced and rapid dose reduction within a small distance beyond. A theoretical tumour with $3 \mathrm{~cm}$ diameter $\left(14.1 \mathrm{cc}-10^{9.7}\right.$ cells) and two SHRS regimens of $54 \mathrm{~Gy}$ in 3 fractions (A) and $30 \mathrm{~Gy}$ in 3 fractions (B) are used as an example (Fig. 1). The dose distributed in surrounding normal tissues is transformed into respective BED doses using $\alpha / \beta$ $=3.0 \mathrm{~Gy}$ (Fig. 1.1). This figure illustrates rapid dose reduction to $40 \%$ of total $\mathrm{BED}_{3}$ at $5 \mathrm{~mm}$ and to about $17 \%$ at $10 \mathrm{~mm}$ distance from the GTV margins (Fig. 1.2). As opposed to the assumed homogeneous dose distribution within the tumour GTV, critical normal tissue/organs receive different, small rates of the planned dose. Thus, their response to SHRS will depend on the number of the FSUs and its target cells involved (volume factor). Other mechanisms (3R's) which also play an important role, depending on the size of single or fraction dose, cannot be ignored [6-10].

\section{Response of brain and spinal cord structures and other organs}

Sometimes mature neurons are considered as target cells, but they are the most radioresistant cells in the CNS,

(1)

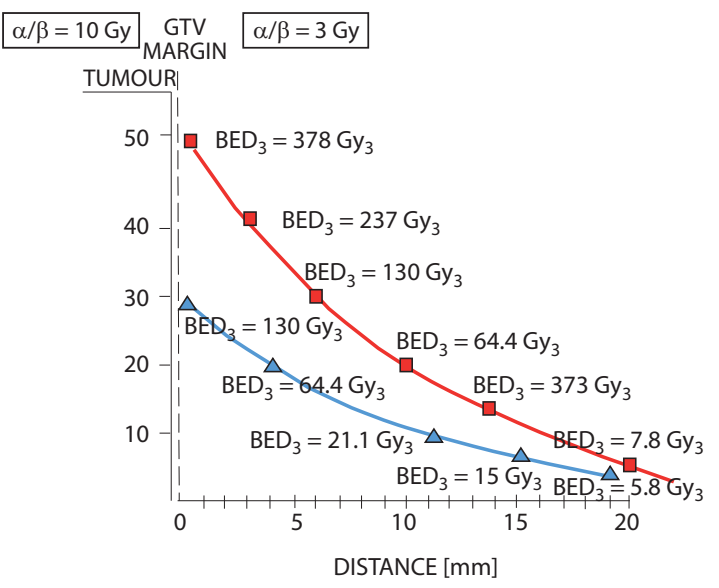

$$
\begin{array}{ll}
\text { (A) } 54 \mathrm{~Gy} / 3 \mathrm{fx} & \text { (B) } 30 \mathrm{~Gy} / 3 \mathrm{fx} \\
\mathrm{BED}_{10}=151 \mathrm{~Gy} & \text { BED }_{10}=60 \mathrm{~Gy}_{10}
\end{array}
$$

and in fact, they are not the primary target, but they do die as a result of different indirect pathological processes $[1,4,7$, 10-12]. Vasculoendothelial cells are the most radiosensitive and likely are the primary target for radiation $[4,7,13]$. Its deceleration induces a cascade of pathological processes which indirectly but irreversibly lead to consequential neural damage and functional dysfunction (myelopathy, necrosis). Endothelial cell damage, mediated by cytokine TNF- $\alpha$, induces a dose-dependent extravasation of serum proteins one day after high-dose irradiation, which is a sign of an impaired blood-brain barrier $[1,2,14]$. Two to three months later, reversible demyelization occurs, which becomes confluent in a dose-dependent manner.

Progressive demyelization, gliosis, and vasogenic oedema lead to further impairment of cellular nutrition $[1,4,5]$. Garcia-Barros et al. and Brown et al. reported that these pathological processes occur after single doses of 8-10 Gy and higher $[11,15]$. The severity of vascular damage and other consequential effects strongly depend on the dose, the irradiated volume of the brain or lengths of the spinal cord [1, 4, 13, 16-20]. Some late effects and syndromes can be transient like Lhermite's syndrome [21], which generally occurs a few months after spinal cord irradiation as a result of transient demyelization. Vascular lesions, oedema, and inflammatory effects in the CNS precede any neurological changes in astrocytes, microglial, loss of oligodendrocytes and subsequently, neurons. Vascular damage also leads to post SHRS late damage of the optic nerve $[18,20]$, and indirectly to obliteration of about $88 \%$ of the vascular malformation (AUM) nidus [4, 22] after the dose of about $23 \mathrm{~Gy}$ $\left(\mathrm{BED}_{3}=199 \mathrm{~Gy}_{3}\right)$.

(2)

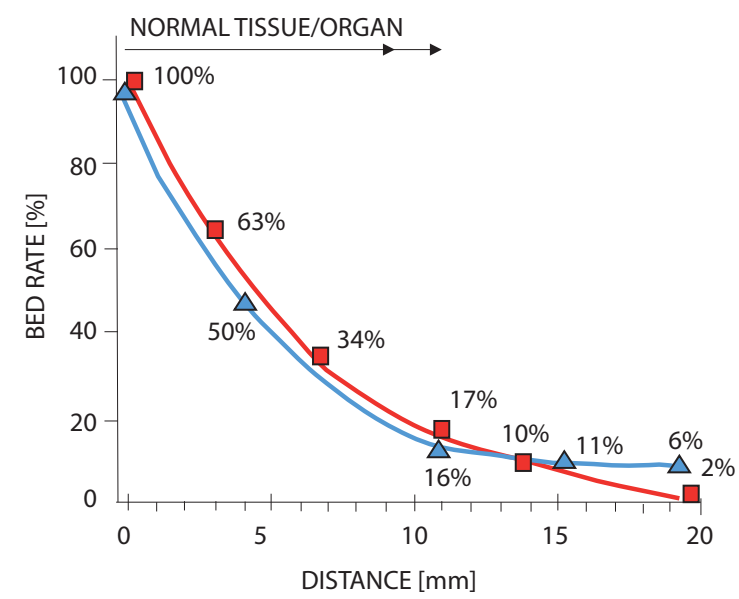

Figure 1. Dose gradient in normal tissue surrounding a theoretical tumour irradiated using SHRS with two different regimens (A) and (B)

(1) - $\mathrm{BED}_{3}$ dose gradient within the distance from GTV margins;

(2) - rates of BED decrease (from Fig. 1.1) vs distance from the GTV 
Vascular damage is not only limited to the CNS but also occurs in other organs. Capillary endothelial cell damage in the lung induces injury of the type II alveolar cells $[4,6$, 18, 23-27], considered by some authors as primary target cells $[1,2]$ in the pulmonary alveolus (FSU). These processes are supported by radiation-induced cytokine TGF- $\beta$ which stimulates collagen formation and contributes to both early and late pulmonary fibrosis. Damage to the microvascular endothelium also induces skin teleangiectases.

Vascular endothelial cells are also a primary target for late heart radiation injury. Their death initiates a sequence of lesions in the myocardial vasculature. These effects lead then to ischemia and finally to myocardial fibrosis $[2,26]$. Neither direct damage to myocytes nor coronary arteries are the main and primary targets.

Nephron is a single FSU in the kidney, but major radiation injury occurs at first in the glomerular capillaries and precedes tubular depletion, which lead to tubular atrophy $[18,29]$. Vascular damage also plays an important role in the late response of the liver $[30,31]$ and pancreas, although the pathobiology of late radiation effects in these organs remains obscure.

In the gastrointentional tract, epithelial mucosal cells are recognized as target cells. Rapidly regenerating foci in the epithelium appear within 7-14 days, and complete epithelial regeneration, for example in the oesophagus, can occur 3 months to 2 years after irradiation. Progressive vascular damage leading to endarteritis is the critical radiation lesion for late effects $[4,6]$, and rapid obliteration of vessels results in gradual slow fibrosis and narrowing of the fine vasculature. The Oesophagus, intestine and bowel are tube-like organs and if instead of a part of the oesophageal wall, the whole circumference of the tube receives a high dose, then vasculoendothelial damage may in the end lead to very severe necrosis and fatal perforation.

Although hypoxia is the result of vascular damage after SHRS, it may sometimes play a protective role. Depending on the intensity of the cell kill, the potential of sublethal damage repair can contribute to recovery of some portion of injuries until the nutritional and microenvironmental condition becomes unfavourable, and then it will induce "avalanche" late damage. Repopulation does not play a role at all, since treatment is usually very short.

There is still a lack of understanding of the role of the immunogenic effects of radiation, especially large doses [7]. Cytotoxic T-cells induced by radiation likely influence tumour regression, but released cytokines can partly play a protective role. Radiation also affects other nonimmune cells of microenvironment as lymphocyte extravasation and facilitates expansion of myeloid-derived suppressive cells. Thus, large dose fractions initiate dichotomous effects of immune functions, that means, they could be simultaneously both immunostimulatory and immunosuppressive.
Thus, they may in some way protect late responding normal tissues, but in the field of SHRS, available data are vague and fragmentary and they mainly come from the bench with no clinical validation. SHRS no doubt induces complex mechanisms of normal tissue response to high single fractionated doses, but these are rather guessed at than quantified and validated.

\section{Normal tissues/organs dose constraints}

Late radiation effects in normal organs occur as a variety of late complications, ranging from those that are confined, moderate and tolerable by patients despite the deteriorating quality of life, to the very severe, life threatening and even fatal. They manifest usually years after treatment and its manifestation is based on probability but not on certainty.

Four to five decades ago, Rubin and Casarett $[2,3]$ defined pathomorphological radiation features in normal tissues and they proposed a series of tolerance doses $\left(\mathrm{TD}_{5 / 5}\right.$ and $\left.\mathrm{TD}_{50 / 5}\right)$. One can however question the adequacy of these terms because "tolerance" refers to patient's reaction to late effects which have already occurred. Thus "Risk Doses $\mathrm{RD}_{5 / 5}$ and $\mathrm{RD}_{50 / 5}$ ", seem more appropriate terms because they correspond to a $5 \%$ or $50 \%$ risk of the occurrence of specific late effects (complications), except for the spinal cord with the constraint $\mathrm{RD}_{1 / 5}$ which should not be surpassed.

The majority of the RD doses and the radiopathobiology of normal tissues/organs responses have been established empirically due to growing knowledge and experience [4] but usually they are rather quasi-quantitavely guessed than precisely estimated. Nowadays, these empirical guidelines should be interpreted cautiously because they do not fully and precisely reflect the underlying complex of pathological and functional processes resulting from differences in dose distribution.

SHRS regimens offer two important strengths. The first is intentionally homogeneous high dose distribution within the tumour GTV (overdosage is accepted) and the second, significant dose decrement within a relatively short distance (in $\mathrm{mm}$ ) from the GTV margins (Fig. 1). Therefore, the dose which is received in all or in part of a critical normal organ and the consequences thereof strongly depend among other factors on its relative localization to the tumour margins.

There are a few different SHRS regimens most often used in practice, generally from 10-30 Gy of single fraction to various doses given in 3,4 or 5 fractions. Using data from Park et al. [9] and Siva et al. [26], $0.4 \times \mathrm{BED}_{2}$ and $0.17 \times \mathrm{BED}_{2}$ for normal lung have been estimated (rates taken from Fig.1) for various SHRS regimens (Tab. I). The results show that $0.17 \times \mathrm{BED}_{2}$ doses (probably except for $60 \mathrm{~Gy}$ and $66 \mathrm{~Gy}$ given in $3 \mathrm{fx}$ ) do not theoretically exceed tolerance constraints for this organ. No late pulmonary complications were noted after delivery of $45 \mathrm{~Gy} / 3$ fx, 50 Gy / 5 fx, 60 Gy 
/ $5 \mathrm{fx}$ and even after $30 \mathrm{~Gy} / 1 \mathrm{fx}$, however $9 \%$ of late lung complications occurred after $30 \mathrm{~Gy} / 1 \mathrm{fx}, 60 \mathrm{~Gy} / 4 \mathrm{fx}$, and surprisingly also $5 \%$ after $24 \mathrm{~Gy} / 3 \mathrm{fx}$. In light of these results, Siva and Slotman [26] rightly ask where is the evidence and what are we doing with it?

A prospective phase I trial on peripheral stage $T_{1}-T_{2}$ NSCLC [24] revealed that $60 \mathrm{~Gy} / 3 \mathrm{fx}\left(0.17 \mathrm{BED}_{2}=112 \mathrm{~Gy}_{2}\right)$ did not exceed the tolerance constraint, but $66 \mathrm{~Gy} / 3 \mathrm{fx}(0.17$ $\mathrm{BED}_{2}=135 \mathrm{~Gy}_{2}$ ) did. It is not easy to establish constraint BEDs for different SHRS regimens (Tab. I). The suggestion that the $\mathrm{BED}_{3}$ of $100 \mathrm{~Gy}_{3}(\alpha / \beta=3.0 \mathrm{~Gy})$ might be a commonly accepted RD dose as a tolerance constraint for late responding normal tissue [8] sounds unreasonabe and raises some uncertainties, at least because dose distribution within the organ at risk or part of it and the distance to the tumour GTV strongly influence differences in the RD constraints.

The Risk Doses (mean and max) presented in Tables II and III have mainly been deduced and compiled based on many data sets published in the literature, more or less detailed and often fragmentary. Morphological and clinical features of late effects are rather concise and sometimes uncertain regarding the volume of the organ involved (e.g. the inner or outer part of the kidney), and it distance to the tumour GTV. Therefore, the RD doses shown in Table II and III should be cautiously interpreted as approximate guidelines rather than obligatory.

SHRS has been primarily used for CNS tumours and later extended also to extracranial tumours. This explains why more detailed data are in Table II than in Table III. Retrospective CFRT and prospective SHRS data allow comparison of the risk of brain necrosis (RBN) depending on the BED values estimated for these two types of radiotherapy. Figure 2 shows that the increasing risk of the RBN correlates with lower SHRS - BEDs than with CFRT-BEDs. Flickinger et al. [6, 22] published interesting and unique data regarding the risk of late injury in various regions of the brain after irradiation with a single dose of $12 \mathrm{~Gy}\left(\mathrm{BED}_{2}=84 \mathrm{~Gy}_{2}\right)$, which depended on localization of the arteriovenous malformation (AVM) in
Table I. Biologically effective doses $\left(\mathrm{BED}_{2.0}\right)$ estimated for a hypothetical normal organ ( $\alpha / \beta=2.0 \mathrm{~Gy}$ ) with distance coefficients to the tumour GTV (taken from Fig. 2) for SHRS regimes from Park et al. [9]

\begin{tabular}{lcc}
\hline $\begin{array}{l}\text { SHRS } \\
\text { regimens } \\
\text { (tumour) }\end{array}$ & \multicolumn{2}{c}{ Normal lung ( $\alpha / \beta=2.0 \mathrm{~Gy})$} \\
\cline { 2 - 3 } & $\begin{array}{c}0.4 \times \mathrm{BED}_{2}{ }^{*} \\
(5 \mathrm{~mm} \text { distance) }\end{array}$ & $\begin{array}{c}0.17 \mathrm{BED}_{2}{ }^{*} \\
\text { (10 mm distance) }\end{array}$ \\
\hline $24 \mathrm{~Gy} / 3 \mathrm{fx}$ & $48 \mathrm{~Gy}_{2}$ & $20 \mathrm{~Gy}_{2}$ \\
$25 \mathrm{~Gy} / 1 \mathrm{fx}$ & $135 \mathrm{~Gy}_{2}$ & $57 \mathrm{~Gy}_{2}$ \\
$30 \mathrm{~Gy} / 1 \mathrm{fx}$ & $192 \mathrm{~Gy}_{2}$ & $82 \mathrm{~Gy}_{2}$ \\
$45 \mathrm{~Gy} / 3 \mathrm{fx}$ & $153 \mathrm{~Gy}_{2}$ & $65 \mathrm{~Gy}_{2}$ \\
$48 \mathrm{~Gy} / 4 \mathrm{fx}$ & $134 \mathrm{~Gy}_{2}$ & $57 \mathrm{~Gy}_{2}$ \\
$50 \mathrm{~Gy} / 5 \mathrm{fx}$ & $172 \mathrm{~Gy}_{2}$ & $51 \mathrm{~Gy}_{2}$ \\
$60 \mathrm{~Gy} / 3 \mathrm{fx}$ & $264 \mathrm{~Gy}_{2}$ & $112 \mathrm{~Gy}_{2}$ \\
$60 \mathrm{~Gy} / 4 \mathrm{fx}$ & $204 \mathrm{~Gy}_{2}$ & $87 \mathrm{~Gy}_{2}$ \\
$60 \mathrm{~Gy} / 5 \mathrm{fx}$ & $168 \mathrm{~Gy}_{2}$ & $71 \mathrm{~Gy}_{2}$ \\
$66 \mathrm{~Gy} / 3 \mathrm{fx}$ & $317 \mathrm{~Gy}_{2}$ & $135 \mathrm{~Gy}_{2}$ \\
\hline
\end{tabular}

* $\mathrm{BED}_{2}$ was calculated for lung in the respective distance from the tumour GTV

the brain with the volume of the AVM (Fig. 3). Historical data by Van Dyk et al. [27] show that RD of about $8 \mathrm{~Gy}\left(\mathrm{BED}_{2}=40\right.$ $\mathrm{Gy}_{2}$ ) correlates with a $5 \%$ risk of late pneumonitis, but it also depends on the irradiated volume (Fig. 4). These examples warn against acceptance the $\mathrm{BED}_{3}$ of $100 \mathrm{~Gy}_{3}$ as the universal cut-off risk dose, because for some organs the BED constraint should not be higher than 40-60 Gy. The kidney constraint dose reported by Timmerman et al. [10] depends on the involved volume of the kidney. If the renal cortex is involved, the critical volume of $200 \mathrm{cc}$ should not receive a single dose higher than $8.4 \mathrm{~Gy}\left(\mathrm{BED}_{2}=45 \mathrm{~Gy}_{2}\right)$, whereas in the case of the renal hilum, the dose constraint for $2 / 3$ of the kidney can receive a single dose of $10.4 \mathrm{~Gy}\left(\mathrm{BED}_{2}=64 \mathrm{~Gy}_{2}\right)$. Nevertheless, both constraints are far below the BED $=100$ Gy, proposed by Yang et al. [8] as "safe" for normal tissues.

Despite various pathoradiobiological mechanisms, the low constraint dose for kidney (as for some other organs as

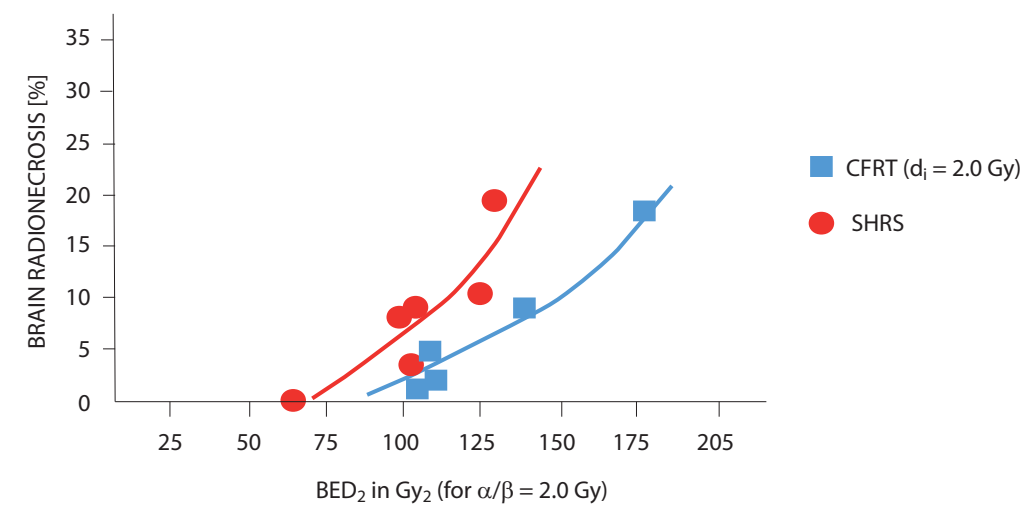

Figure 2. Comparison of radiation brain necrosis related to the BED doses of SHRS (๑) with that of CFRT ( $\square$ ) (based on data [4] and [11]) 


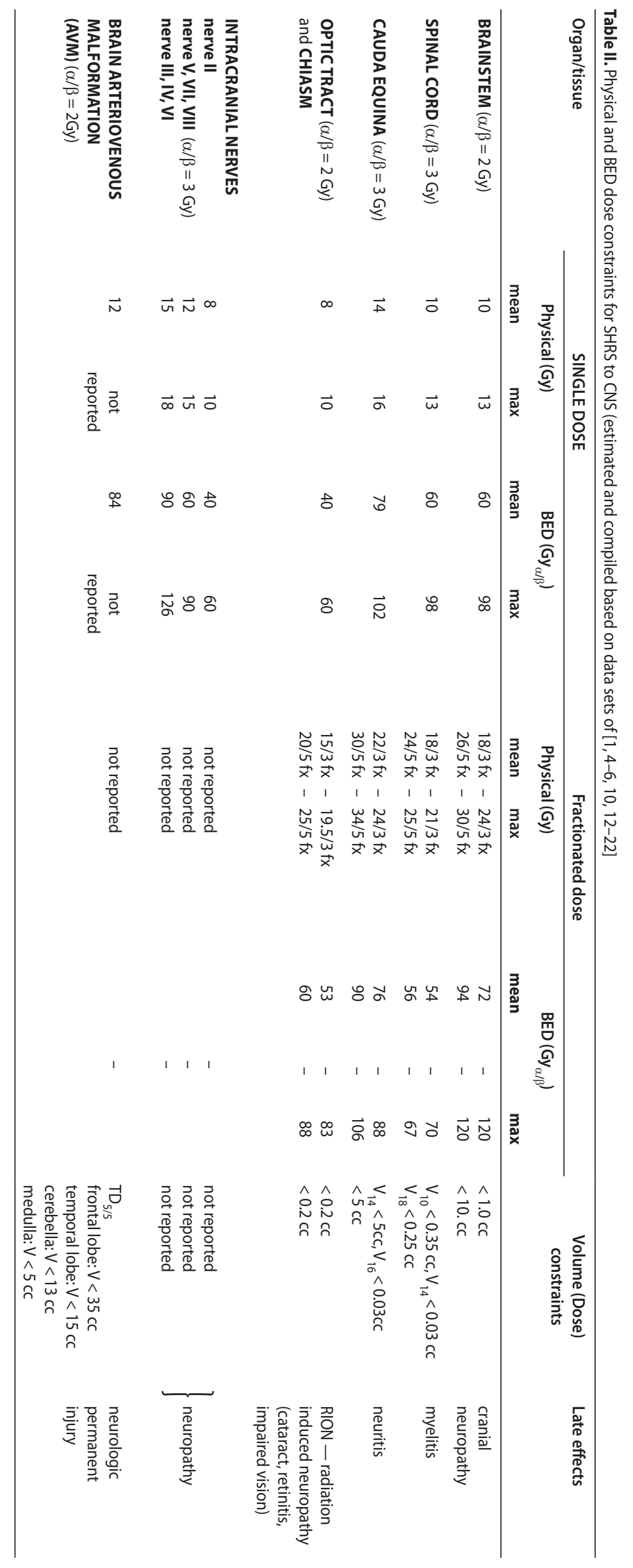




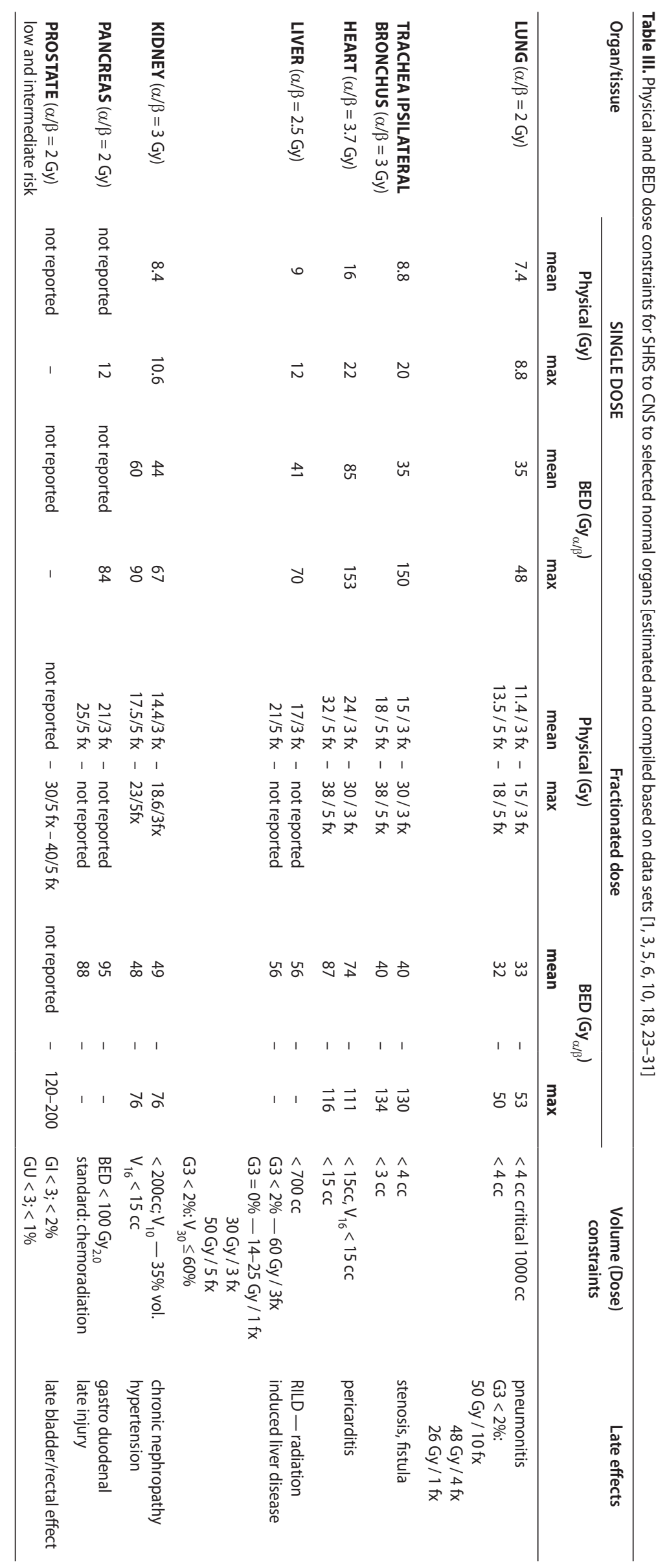




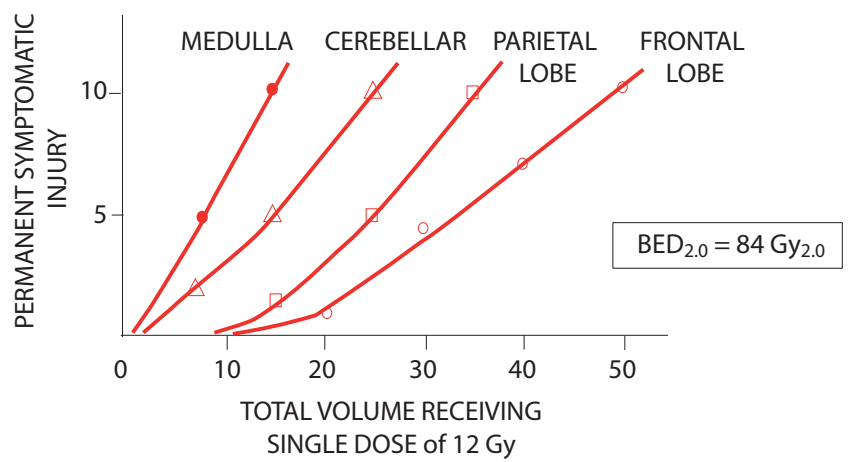

Figure 3. Incidence of neurological sequence in various parts of the brain depending on the arteriovenous malformation (AVM) volume irradiated with a single dose of $12 \mathrm{~Gy}\left(\mathrm{BED}_{2}=84 \mathrm{~Gy}_{2}\right)$ (based on [22])

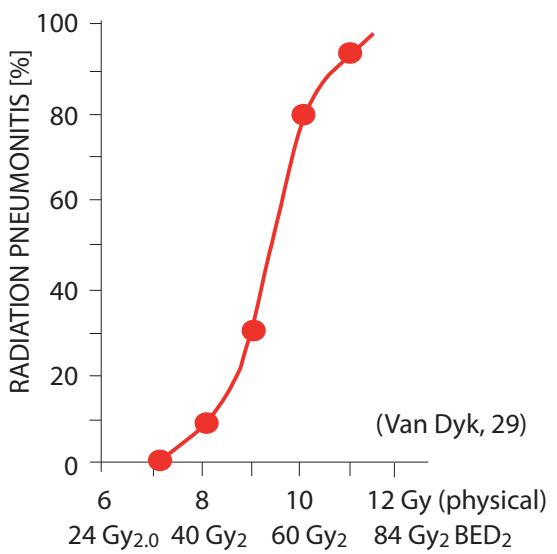

SINGLE DOSE TO LUNG

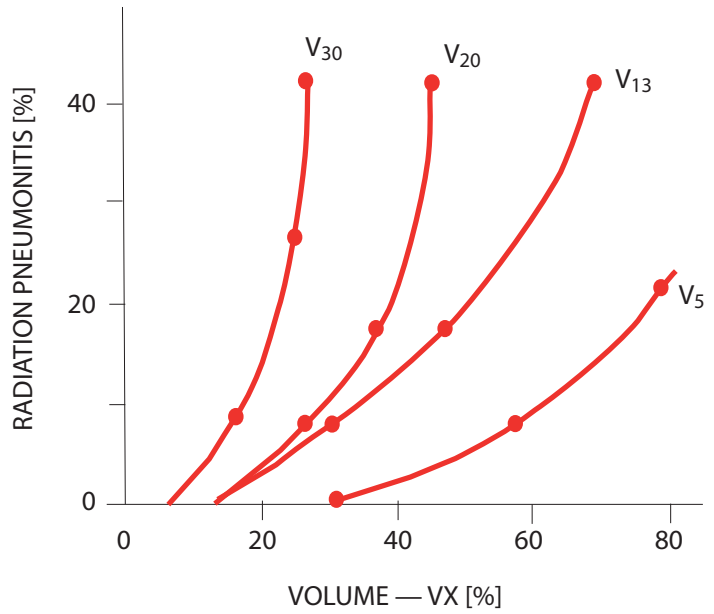

Figure 4. Incidence of radiation pneumonitis depending on the size of $\mathrm{s}$ single dose $(\mathbf{A})$ and $\mathrm{V}_{(\mathrm{BED})}$ in irradiated volume (B)

well) reflects not only a low $\alpha / \beta$ value but also depends on the FSU organization. The kidney is an excellent example of the importance of the organ's cellular organization. A kidney contains more or less about $10^{11}$ target clonogenic tabular cells organized as $10^{4}$ cells in each of $10^{7}$ nephrons (FSUs). From the radiobiological point of view, most of them will recover after a dose reducing survival to $10^{-4}$ (37\% of nephrons will survive). However, if renal target cells were organized in a different way, namely $10^{7}$ target cells in $10^{4}$ nephrons, then $37 \%$ of nephrons would survive after reduction of cell survival to no more than $10^{-7}$, which would result in an increase of constraint RD by $75 \%$ (7/4). This example shows how important collection of detailed and validated data on dose/fractionation is, distributed to all or a defined part of a normal organ, on dose gradients distributed within them and on specific, not general, clinical and functional late injures, including the time of its occurrence.

In the present review, data have been selected and interpreted as precisely as possible. However, we have not been able to clarify some uncertainties and "blank points". Therefore, in conclusion, it is advised to consider cautiously presented and compiled dose constraints (RD) for various normal organs, with some measure of criticism because many of them are not definitive, obligatory and are as yet unvalidated, but they are rather approximated guidelines.

Conflict of interest: none declared

\section{prof. Bogusław Maciejewski, MD, PhD}

Maria Skłodowska-Curie Memorial Cancer Centre and Institute of Oncology

Deptartment of Radiotherapy

ul. Wybrzeże Armii Krajowej 15

44-101 Gliwice, Poland

e-mail:boguslaw.maciejewski@io.gliwice.pl

Received: 4 Apr 2018

Accepted: 10 Apr 2018

\section{References}

1. McBride WH, Withers HR. Biological basis of radiation therapy. In: Perez and Brady's principles and practice of radiation oncology. Halperin $E$, Perez CA, Luther W et al. (eds). 5th ed. Philadelphia: Lippincott Williams and Wilkins, 2004: 76-108.

2. Rubin P, Casarett GW. Clinical radiation pathology. Vol. I, II. Philadelphia: WB Saunders, 1968

3. Rubin P. The law and order of radiation sensitivity, absolute vs relative. Front Radiat Ther Oncol 1989; 23: 7-40. 
4. Kirkpatrick JP, Milano MT, Coustine LS et al. Late effects and QUANTEC. In: Perez and Brady's principles and practice of radiation oncology. Halperin E, Perez CA, Luther W et al. (eds). Philadelphia: Lippincott Williams and Wilkins, 2013; 296-329.

5. Gross MW, Engenhart-Cabillis R. Normal tissue reactions after linac-based radiosurgery and stereotactic radiotherapy. Front Radiat Ther Oncol 2002; 37: 140-150.

6. Flickinger JC, Nirajan A. Stereotactic radiosurgery and radiotherapy. In: Perez and Brady's principles and practice of radiation oncology. Halperin E, Perez CA, Luther W et al. (eds). Philadelphia: Lippincott Williams and Wilkins, 2013: 351-361.

7. Shabason JE, Minn AJ. Radiation and immune checkpoint blockage: from bench to clinic. Semin Radiat Oncol 2017; 27: 289-298.

8. Yang J, Fowler JF, Lamond JP et al. Red shell: defining a high-risk zone of normal tissue damage in stereotactic body radiation therapy. Int $J$ Radiat Oncol Biol Phys 2010; 77: 903-909.

9. Park C, Papiez L, Zhang $S$ et al. Universal survival curve and single fraction equivalent dose: useful tools in understanding potency of ablative radiotherapy. Int J Radiat Oncol Biol Phys 2008; 70: 847-852.

10. Timmerman RD. An overview of hyperfractionation and introduction to this issue of seminars in radiation oncology. Semin Radiat Oncol 2008; 18: 215-222.

11. Brown JM, Koong AC. High-dose single-fraction radiotherapy: exploiting a new biology? Int J Radiat Oncol Biol Phys 2008; 71: 324-325.

12. Lawrence YR, Li XA, Naga I et al. Radiation dose-volume-effect in the brain. Int J Radiat Oncol Biol Phys 2010; 76 (3 Suppl): S20-27.

13. Mayo C, Yorke E. Merchant TE. Radiation associated brainstem injury. Int J Radiat Oncol Biol Phys 2010; 76 (3 Suppl): S36-41.

14. Nakata $\mathrm{H}$, Yoshimine T, Murasawa A et al. Early blood-brain barrier disruption after high-dose single-fraction irradiation in rats. Acta Neurochir 1995; 136: 82-86.

15. Garcia-Barros M, Paris F, Cordon-Cardo C et al. Tumor response to radiotherapy regulated by endothelial cell apoptosis. Science 2003; 300: 1155-1159.

16. Kirkpatrick JP, van der Kogel AJ, Schultheiss TE. Radiation dose-volume effect in the spinal-cord. Int J Radiat Oncol Biol Phys 2010; 76 (3 Suppl): S42-49.
17. Katsoulakis E. Kumar K Laufer I et al. Stereotactic body radiotherapy in the treatment of spinal metastases. Semin Radiat Oncol 2017; 27: 209-217.

18. Fajardo LF. Morphology of radiation effects on normal tissues. In Perez CA, Brady LW (eds). Principles and practice of radiation oncology. Philadelphia: JB Lippincott Co, 1992: 114-123.

19. Ang KK, Price RE, Stephens LC et al. The tolerance of primate spinal cord to re-irradiation. Int J Radiat Oncol Biol Phys 1993; 25: 459-464.

20. Mayo C, Martel MK, Marks LB et al. Radiation dose-volume effects of optic nerves and chiasm. Int J Radiat Oncol Biol Phys 2010; 76 (3 Suppl): S28-35.

21. Jones A. Transient radiation myelopathy (with reference to Lhermitte's sign of electrical paresthesia). Br J Radiol 1964; 37: 727-744.

22. Flickinger JF, Kondziolka D, Pollock BE et al. Complications from arteriovenous malformation radiosurgery: multivariate analysis and risk modeling. Int J Radiat Oncol Biol Phys 1997; 38: 485-490.

23. Shah JL, Loo BW. Stereotactic ablative radiotherapy for early-stage lung cancer. Semin Radiat Oncol 2017: 27: 218-228.

24. Timmerman R, Papiez L, McGarry R et al. Extracranial stereotactic radioablation: results of a phase I study in medically inoperable stage I non-small cell lung cancer. Chest 2003; 124: 1946-1955.

25. Marks LB, Bentzen SM, Desay JO et al. Radiation dose-volume effect in the lung. Int J Radiat Oncol Biol Phys 2010; 76 (3 Suppl): S70-76.

26. Siva S, Slotman BJ. Stereotactic ablative body radiotherapy for lung metastases: where is the evidence and what are we doing with it? Semin Radiat Oncol 2017: 27: 229-239.

27. Van Dyk J, Keane TJ, Kan S et al. Radiation pneumonitis following large single dose irradiation: a re-evaluation based on absolute dose to lung. Int J Radiat Oncol Biol Phys 1981; 7: 461-467.

28. Fajardo LF, Stewart JR. Pathogenesis of radiation-induced myocardial fibrosis. Lab Invest 1973; 29: 244-257.

29. Glatstein E, Fajardo LM, Brown JM. Radiation injury in the mouse kidney - I. Sequential light microscopic study. Int J Radiat Oncol Biol Phys 1977; 2: 933-943.

30. Goodman KA, Kavanagh BD. Stereotactic body radiotherapy for live metastases. Semin Radiat Oncol 2017; 27: 240-246.

31. Murray LJ, Dawson LA. Advances in stereotactic body radiotherapy for hepatocellular carcinoma. Semin Radiat Oncol 2017; 27: 247-255. 